\title{
Penicillin-binding Protein Inactivation by Human Neutrophil Myeloperoxidase
}

Robert M. Rakita and Henry Rosen

Departments of Medicine, University of Washington, Seattle, Washington 98195, and Swedish Hospital Medical Center, Seattle, Washington 98104

\begin{abstract}
Myeloperoxidase (MPO), $\mathrm{H}_{2} \mathrm{O}_{2}$, and chloride comprise a potent antimicrobial system believed to contribute to the antimicrobial functions of neutrophils and monocytes. The mechanisms of microbicidal action are complex and not fully defined. This report describes the MPO-mediated inactivation, in Escherichia coli, Staphylococcus aureus, and Pseudomonas aeruginosa, of a class of cytoplasmic membrane enzymes (penicillinbinding proteins, PBPs) found in all eubacteria, that covalently bind $\beta$-lactam antibiotics to their active sites with loss of enzymatic activity. Inactivation of "essential" PBPs, including PBP1-PBP3 of E. coli, leads to unbalanced bacterial growth and cell death. MPO treatment of bacteria was associated with loss of penicillin binding by PBPs, strongly suggesting PBP inactivation. In $E$. coli, $\mathrm{PBP}$ inactivation was most rapid with PBP3, where the rate of decline in binding activity approximated but did not equal loss of viability. Changes in $E$. coli morphology (elongation), observed just before bacteriolysis, were consistent with early predominant inactivation of PBP3. We conclude that inactivation of essential PBPs is sufficient to account for an important fraction of MPO-mediated bactericidal action. This feature of MPO action interestingly recapitulates an antibacterial strategy evolved by $\beta$-lactam-producing molds that must compete with bacteria for limited ecologic niches. (J. Clin. Invest. 1991. 88:750-754.) Key words: phagocytes - microbicidal mechanisms - Escherichia coli $\bullet \beta$-lactam antibiotics $\bullet$ Staphylococcus aureus
\end{abstract}

\section{Introduction}

Myeloperoxidase (MPO) ${ }^{1}$, an enzyme found in the azurophil granules of neutrophils, is a major component of the oxygendependent antimicrobial systems of phagocytes $(-1)$. When combined with $\mathrm{H}_{2} \mathrm{O}_{2}$, synthesized by the respiratory burst, and chloride, it forms a number of powerful oxidants $(2,3)$. Lesions induced by MPO-derived oxidants have been best characterized for sites at the bacterial cytoplasmic membrane. These include loss of energy charge and nutrient transport (4). Determining whether any of these effects is either necessary or sufficient to account for loss of microbial viability has been an elusive goal.

Address correspondence to Dr. Henry Rosen, Swedish Hospital Medical Center, Department of Medicine, 747 Summit Avenue, Seattle, WA 98104.

Received for publication 16 August 1990 and in revised form 15 March 1991.

1. Abbreviations used in this paper: MPO, myeloperoxidase; PBP, penicillin-binding protein.

J. Clin. Invest.

(c) The American Society for Clinical Investigation, Inc 0021-9738/91/09/0750/05 \$2.00

Volume 88, September 1991, 750-754
Penicillin-binding proteins (PBPs), found in the cytoplasmic membrane of all eubacteria (5), mediate the synthesis, degradation, and remodeling of peptidoglycan cell wall components $(6,7)$. $\beta$-lactam antibiotics act by binding to and inactivating PBPs, disrupting balanced PBP activity and resulting in bacterial death. Clinically important antibiotic resistance may be due to the emergence of PBPs with a lower affinity for $\beta$-lactams (8-13).

Because PBP inactivation is microbicidal and because PBPs are located in the bacterial cytoplasmic membrane at sites potentially accessible to MPO-derived oxidants, we investigated the effects of the MPO system on the penicillin-binding properties of Escherichia coli, Pseudomonas aeruginosa, and Staphylococcus aureus, and compared PBP inactivation with loss of microbial viability.

\section{Methods}

Special reagents. Human MPO was prepared from leukocytes obtained from a patient with chronic myelogenous leukemia, as previously described (14). Other reagents were obtained from Sigma Chemical Co., St. Louis, MO, except xanthine oxidase (Boehringer Mannheim, Indianapolis, IN), benzyl penicillin $N$-ethyl piperidine salt, [phenyl- ${ }^{3} \mathrm{H}$ ] and $\mathrm{EN}^{3}$ HANCE (Du Pont Co., Wilmington, DE).

Bacterial strains. Escherichia coli (ATCC 11775; American Type Culture Collection, Rockville, MD), Pseudomonas aeruginosa (ATCC 27853), and Staphylococcus aureus (502A) were maintained on blood agar plates, grown overnight in trypticase soy broth, then diluted 50100 -fold and grown for 3-4 h. Organisms were harvested in $\log$ phase, washed twice, and suspended to the required absorbance at $540 \mathrm{~nm}$.

Microbicidal systems. MPO: Nonenzymatic components indicated in the legends to figures were prewarmed in 125 -ml flasks in an oscillating water bath at $37^{\circ} \mathrm{C}$, and bacteria were added $\sim 1 \mathrm{~min}$ before the initiation of the reaction with MPO and glucose oxidase. At intervals, the reaction was stopped with $1 \mathrm{mM}$ azide, viable bacteria were determined by the pour plate method (15), and cells were pelleted and stored at $-80^{\circ} \mathrm{C}$.

Xanthine oxidase or gentamicin. E. coli were exposed to $50 \mu \mathrm{g} / \mathrm{ml}$ gentamicin or to a xanthine oxidase/acetaldehyde microbicidal system described in the legend to Fig. $1 B(16)$. At intervals, samples were removed for viability determination and cells were pelleted immediately and stored at $-80^{\circ} \mathrm{C}$.

Membranes. For $E$. coli or $P$. aeruginosa frozen cells were thawed, washed once, and suspended in $30 \mathrm{mM}$ Tris, $\mathrm{pH} \mathrm{8.0,} \mathrm{containing} 5$ $\mathrm{mg} / \mathrm{ml}$ lysozyme and $10 \mathrm{mM}$ K-EDTA. After $10 \mathrm{~min}$ on ice, samples were incubated with $10 \mu \mathrm{g} / \mathrm{ml}$ DNAse, $10 \mu \mathrm{g} / \mathrm{ml} \mathrm{RNAse,} \mathrm{and} 20 \mathrm{mM}$ $\mathrm{MgSO}_{4}$ for an additional $10 \mathrm{~min}$. Membranes were collected by centrifugation at $50,000 \mathrm{~g}$ for $30 \mathrm{~min}$ at $4^{\circ} \mathrm{C}$ and suspended in $50 \mathrm{mM}$ sodium phosphate, $\mathrm{pH} 7.0$, to a protein concentration of $10-20 \mu \mathrm{g} / \mathrm{ml} \mathrm{(17).}$

$S$. aureus membranes were prepared by incubating thawed cells suspended in $50 \mathrm{mM}$ potassium phosphate, pH 7.9, with $100 \mu \mathrm{g} / \mathrm{ml}$ lysostaphin, $10 \mu \mathrm{g} / \mathrm{ml} \mathrm{DNAse,} 10 \mu \mathrm{g} / \mathrm{ml} \mathrm{RNAse,} \mathrm{and} 10 \mathrm{mM} \mathrm{MgSO}_{4}$ at $37^{\circ} \mathrm{C}$ for $30 \mathrm{~min}$. Membranes were pelleted at $50,000 \mathrm{~g}$ for $60 \mathrm{~min}$ at $4^{\circ} \mathrm{C}$ and suspended in $50 \mathrm{mM}$ sodium phosphate, $\mathrm{pH} \mathrm{7.0,} \mathrm{to} \mathrm{a} \mathrm{protein}$ concentration of $5-10 \mu \mathrm{g} / \mathrm{ml}$.

Penicillin-binding proteins. Bacterial membranes were incubated with $5 \mu \mathrm{g} / \mathrm{ml}$ benzyl penicillin $N$-ethyl piperidine salt, [phenyl- ${ }^{3} \mathrm{H}$ ] for $10 \mathrm{~min}$ at $37^{\circ} \mathrm{C}$. Sample buffer (18) was added and samples were 
boiled for $5 \mathrm{~min}$. SDS-PAGE was performed using $8 \%$ running gels, $4 \%$ stacking gels, at $50 \mathrm{~V}$ for $16 \mathrm{~h}$, with $200 \mu \mathrm{g}$ protein per lane. Gels were stained with Coomassie blue and prepared for fluorography with EN ${ }^{3}$ HANCE. Examination of Coomassie-stained gels before addition of $\mathrm{EN}^{3} \mathrm{HANCE}$ showed no difference in protein staining between lanes. Dried gels were placed next to preflashed Kodak X-omat AR-2 film at $-80^{\circ} \mathrm{C}$ for $2-3 \mathrm{mo}$. Densitometry was performed using a video densitometry and analysis system (Visage 2000; Biolmage Corp., Ann Arbor, MI), and PBP activity for each band was expressed as the percentage (mean $\pm \mathrm{SE}$ ) of the integrated band intensity at $0 \mathrm{~min}$.

Bacterial morphology. E. coli or $P$. aeruginosa were incubated with the microbicidal system of interest and, at intervals, samples were applied to glass slides, air dried, heat fixed, and stained with safranine for 60 s. Slides were examined with a laser scanning confocal microscope (MRC-500; Bio-Rad Microscience, Cambridge, MA) and the lengths of 30 organisms/sample were determined. Results were averaged for three separate experiments and data were compared using Student's twotailed $t$ test.

\section{Results}

Incubation of $E$. coli with a microbicidal system consisting of human MPO, $\mathrm{H}_{2} \mathrm{O}_{2}$, and chloride, resulted in progressive loss of viability, which was not observed when sodium chloride was replaced by isotonic sodium sulfate. At intervals, $E$. coli were
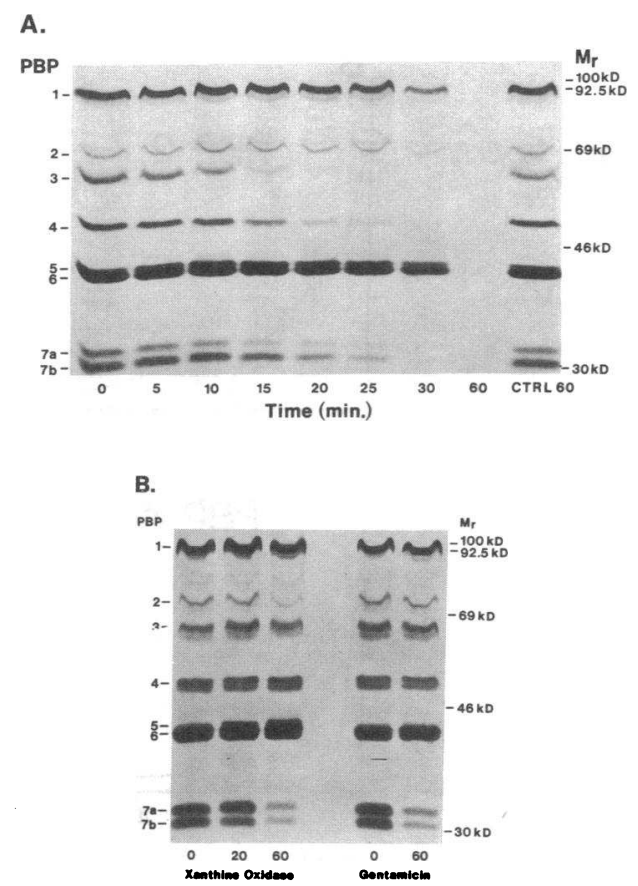

Figure 1. Effect of microbicidal systems on E. coli penicillin-binding proteins. $(A) E$. coli were exposed to a microbicidal MPO system containing (per ml) $10^{9}$ bacteria, $0.18 \mathrm{U}$ of MPO, $0.23 \mathrm{U}$ of glucose oxidase, $0.1 \mathrm{M} \mathrm{NaCl}, 0.04 \mathrm{M} \mathrm{Na}$ acetate, $\mathrm{pH} 5.0,0.01 \mathrm{M}$ glucose, $0.01 \mathrm{M} \mathrm{Na}_{2} \mathrm{SO}_{4}$, and $0.05 \mathrm{mg}$ gelatin (27) for 0-60 min. For the control system, sodium chloride was replaced with $0.067 \mathrm{M}$ sodium sulfate (control 60). At indicated intervals samples were labeled with ${ }^{3} \mathrm{H}$-benzyl penicillin and fluorographed as described in Methods. $(B)$ $E$. coli were exposed to $50 \mu \mathrm{g} / \mathrm{ml}$ gentamicin or a microbicidal xanthine oxidase/acetaldehyde system containing (per ml) $4 \times 10^{7}$ E. coli $0.075 \mathrm{M}$ Na phosphate, $\mathrm{pH} 7.0,0.05 \mathrm{M} \mathrm{Na}_{2} \mathrm{SO}_{4}, 15 \mu \mathrm{M} \mathrm{FeSO}_{4}, 0.06$ $\mathrm{U}$ xanthine oxidase, and $0.75 \mu \mathrm{l}$ acetaldehyde (16). PBPs are numbered to the left according to Spratt (28), mobility of molecular size markers are indicated to the right, and time of incubation is on the bottom.
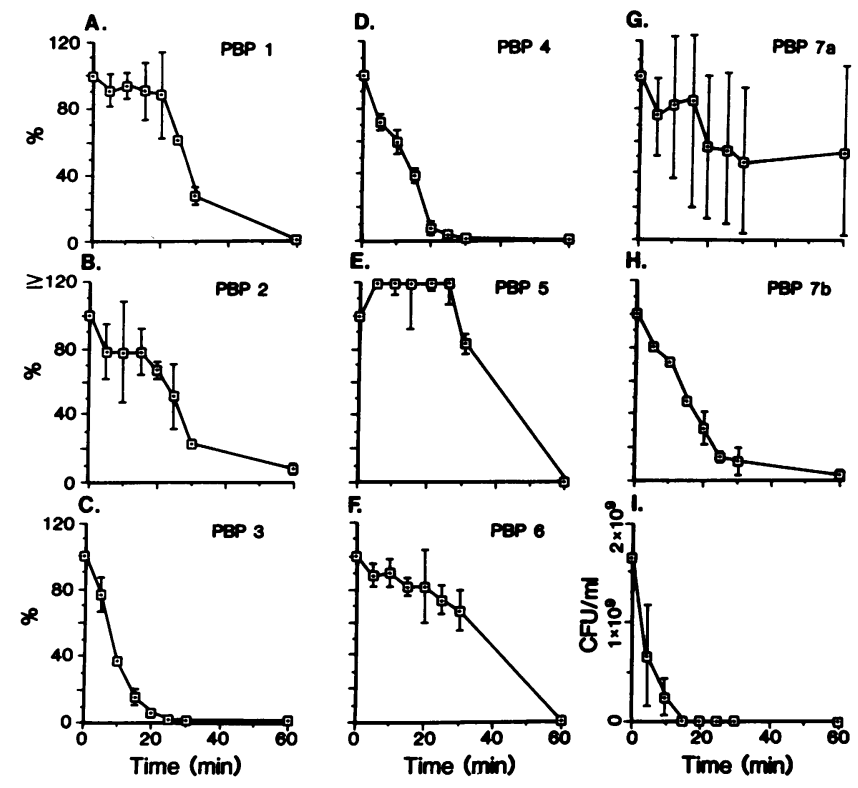

Figure 2. Inhibition of $E$. coli penicillin binding by MPO-derived oxidants. $(A)$ PBP1; (B) PBP2; $(C)$ PBP3; $(D)$ PBP4; $(E)$ PBP5; $(F)$ PBP6; ( $G$ ) PBP7a; $(H)$ PBP7b; (I) microbial viability. PBP binding activity was expressed as the percentage (mean $\pm \mathrm{SE}, n=2$ ) of the integrated band intensity at $0 \mathrm{~min}$.

analyzed for membrane penicillin binding activity as described in Methods. Each of the expected PBPs, designated 1-7b, was detectable at the beginning of the incubation (Fig. $1 A, 0 \mathrm{~min}$ ), but penicillin binding was completely lost after an hour's incubation with the complete MPO system (Fig. $1 \mathrm{~A}, 60 \mathrm{~min}$ ). This effect was not attributable to long-lived oxidants ( 3 ) since addition of reducing agents, $1 \mathrm{mM} 2$-mercaptoethanol, dithiothreitol, or thiosulfate, appeared to have no effect on the relationships between PBP activity and microbial viability (data not shown). PBPs from E. coli exposed to the control MPO system were not significantly affected (Fig. $1 A$, control 60). PBPs were not significantly affected by microbicidal systems mediated by gentamicin or the oxidizing system xanthine oxidase/acetaldehyde (Fig. $1 B$ ), indicating that PBP inactivation was not a simple consequence of cell death.

Rates of MPO-mediated inactivation among PBPs varied considerably (Fig. 2). Binding activity of PBPs 3, 4, and $7 \mathrm{~b}$ (Fig. $2, C, D$, and $H$ ) declined most rapidly, with $50 \%$ loss of activity after 10-15 min exposure. PBPs 1, 2, 5, 6, and 7a (Fig. 2, $A, B$, $E, F$, and $G$ ) were the most resistant to MPO, with retention of $>50 \%$ activity after $25-60 \mathrm{~min}$. The decline in $E$. coli viability induced by MPO is shown for comparison in Fig. $2 I$. E . coli viability in the xanthine oxidase/acetaldehyde system was: 0 $\min =4.0 \times 10^{7} \mathrm{CFU} / \mathrm{ml}, 20 \mathrm{~min}=2.3 \times 10^{7}, 60 \mathrm{~min}=1$ $\times 10^{2}$; for gentamicin: $0 \mathrm{~min}=1.68 \times 10^{8}, 60 \mathrm{~min}=1 \times 10^{2}$.

Similar results were obtained with $P$. aeruginosa (Fig. 3) and $S$. aureus (Fig. 4). Each of the PBPs, labeled 1a-5 for $P$. aeruginosa and 1-4 for $S$. aureus, was present at $0 \mathrm{~min}$ and had almost completely disappeared by $60 \mathrm{~min}$ incubation with the complete MPO system, while exposure to the control MPO system had no effect. A new band of penicillin binding activity in $P$. aeruginosa, labeled PBP4' (Fig. 3) appeared after 5 min exposure to the MPO system, and declined from $10 \mathrm{~min}$ onwards. 


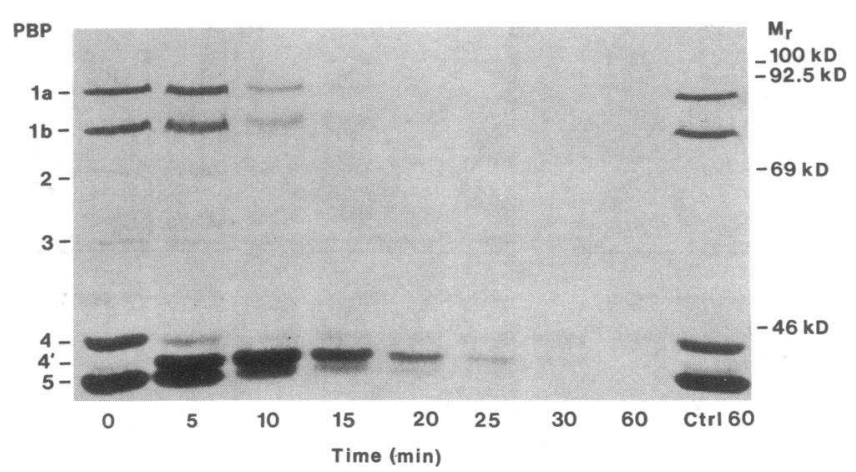

Figure 3. Effect of the MPO system on P. aeruginosa PBPs. The MPO system was as described in Fig. 1, except that the bacteria was $P$. aeruginosa, the $[\mathrm{MPO}]=0.30 \mathrm{U} / \mathrm{ml}$, and the reaction mixture also contained $1 \mathrm{mM} \mathrm{MgSO}_{4}$.

$P$. aeruginosa PBPs 1a, 1b, 4, and 5 declined rapidly, (Fig. $5, A, B, E$, and $G$ ) with $50 \%$ loss of activity after 0-10 min exposure, while PBPs 2 and 3 retained $50 \%$ of their activity until 20-30 min (Fig. 5, $C$ and $D$ ). $S$. aureus PBPs 1, 3, and 4 (Fig. 6, $A, C$, and $D$ ) also fell very rapidly in response to MPO, with only $0-10 \%$ activity remaining after $5 \mathrm{~min}$, and PBP2 declined more slowly (Fig. 6 B). The loss of bacterial viability in response to the MPO system for $P$. aeruginosa and $S$. aureus can be seen in Fig. $5 H$ and Fig. $6 E$, respectively.

For $E$. coli, loss of microbial viability correlated best with loss of penicillin binding activity of PBP3 $(r=0.91)$. For $P$. aeruginosa, good correlations were found for PBPs 1a, $1 \mathrm{~b}$, and $5(r=0.91,0.94$, and 0.91 , respectively). For $S$. aureus, loss of viability correlated best with a decline in PBP2 $(r=0.93)$, though inactivation of PBPs 1,3 , and 4 actually preceded killing.

In $E$. coli, selective, antibiotic-mediated inactivation of PBP3 results in the formation of long filamentous cells (19), forming a basis for the view that PBP3 is important for septation of the cell wall during division (20). The early, predominant inactivation of PBP3 after MPO exposure suggested that growth observed during or shortly after incubation with the MPO system might result in the formation of unusually long rods. Indeed, microscopic examination indicated an increase in the average length of MPO-treated $E$. coli, from a baseline value of $1.56 \pm .03(\mathrm{SE}) \mu \mathrm{m}$, by $0.12 \pm .04 \mu \mathrm{m}$ at $15 \mathrm{~min}(P$ $<0.05)$ and $0.19 \pm .05 \mu \mathrm{m}$ at $30 \mathrm{~min}(P<0.01)$. Illustrative

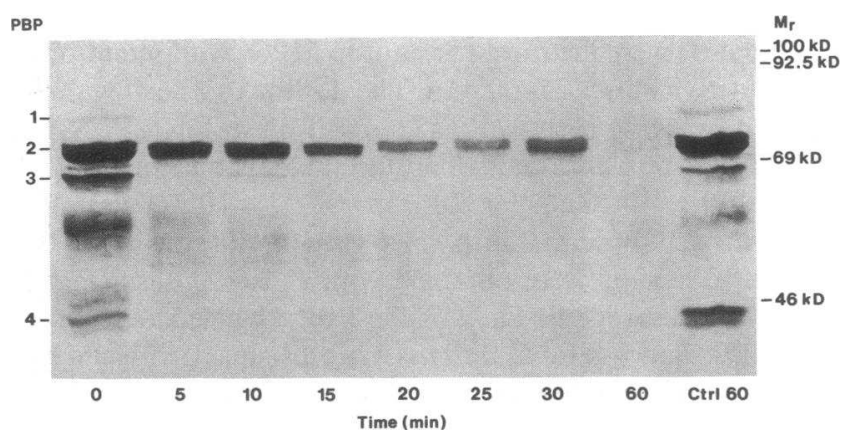

Figure 4. Effect of the MPO system on $S$. aureus PBPs. The MPO system was as described in Fig. 1, except that the bacteria was $S$. aureus, the $[\mathrm{MPO}]=0.08 \mathrm{U} / \mathrm{ml}$, the [glucose oxidase] $=0.20 \mathrm{U} / \mathrm{ml}$, and there was no gelatin.
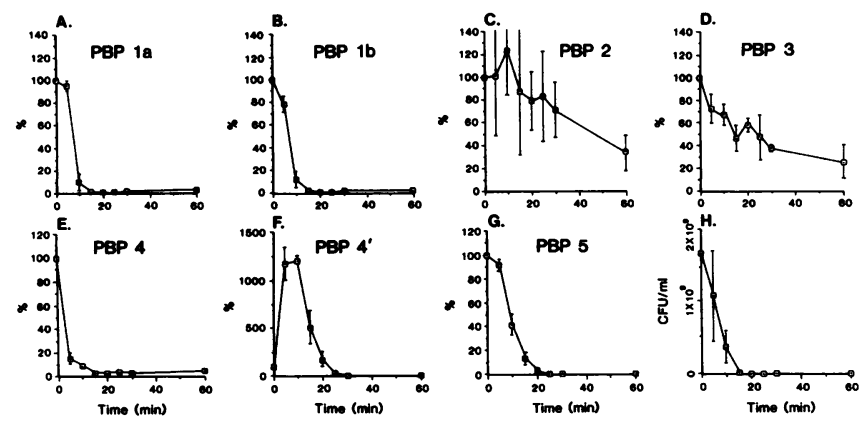

Figure 5. Inhibition of $P$. aeruginosa $\mathrm{PBP}$ activity after MPO exposure. (A) PBP 1a; (B) PBP 1b; (C) PBP2; (D) PBP3; (E) PBP4; $(F)$ PBP4'; $(G)$ PBP5; $(H)$ microbial viability.

photomicrographs are reproduced in Fig. 7 and show one of the long filamentous forms occasionally observed in the MPO exposed group. Although changes in length could have been secondary to other factors such as nutritional (21) or nonspecific oxidant stress (22), neither filamentous forms nor overall increases in cell length were observed among organisms treated for $30 \mathrm{~min}$ either with buffered chloride (change $=0.00 \pm .04$ $\mu \mathrm{m})$, with the chloride deficient, control MPO system
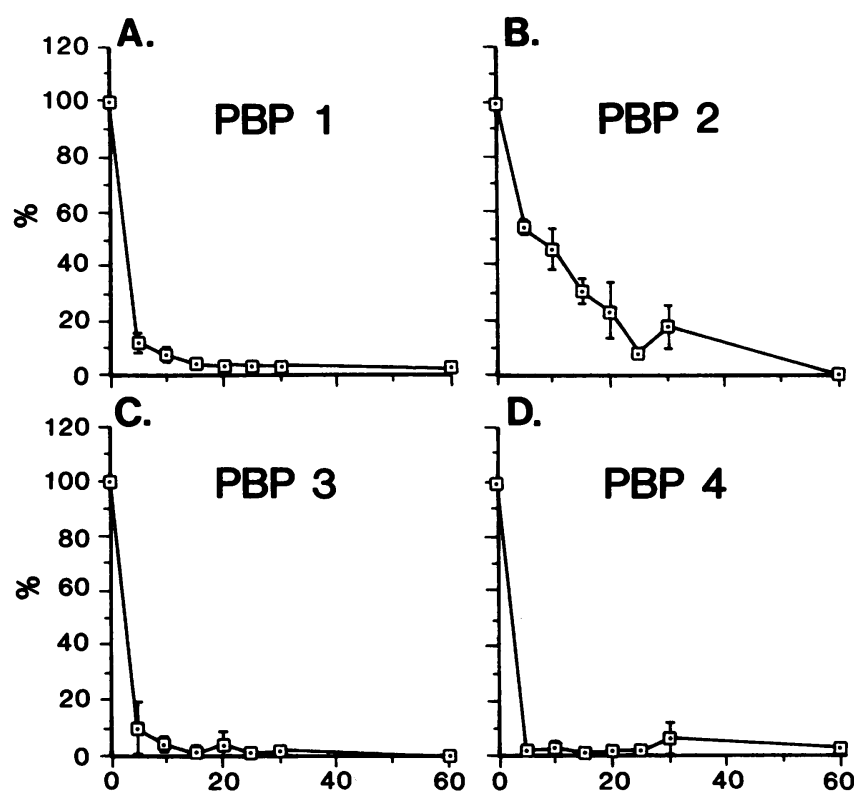

D.

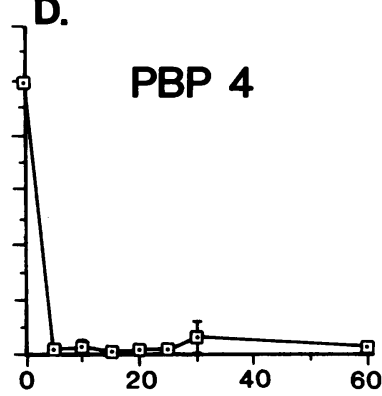

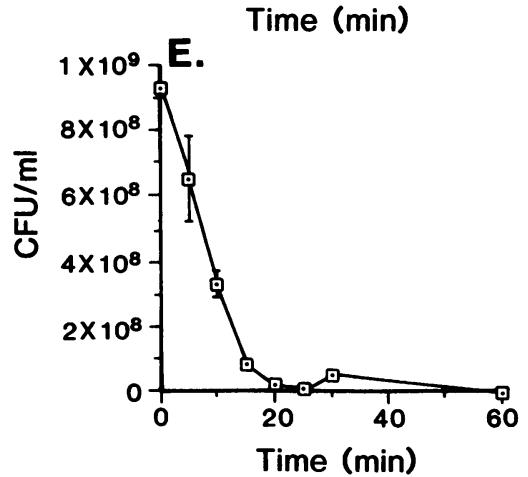

Figure 6. Inhibition of $S$. aureus PBP activity after MPO exposure. $(A) \mathrm{PBP} 1 ;(B) \mathrm{PBP} 2 ;(C) \mathrm{PBP} 3 ;(D) \mathrm{PBP} 4 ;(E)$ microbial viability. 

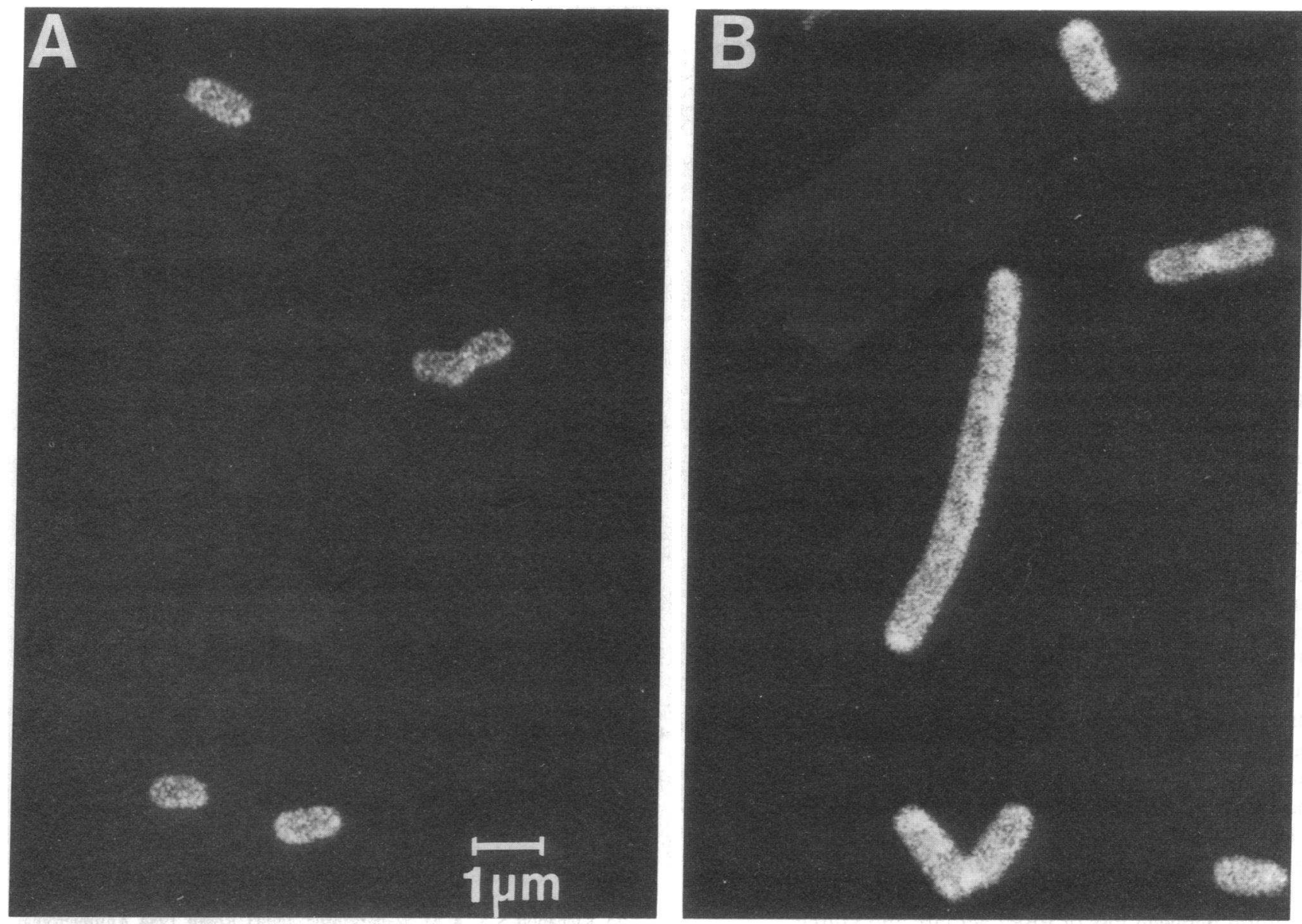

Figure 7. E. coli morphology after exposure to the MPO system. Photomicrographs of $E$. coli after $(A) 0$ min and $(B) 30$ min incubation with the MPO system, as described in Fig. 1. E. coli were stained with safranine and examined as described in Methods.

$(0.07 \pm .04 \mu \mathrm{m})$, with $50 \mu \mathrm{g} / \mathrm{ml}$ gentamicin $(0.11 \pm .06 \mu \mathrm{m})$ or with the xanthine oxidase/acetaldehyde system $(0.01 \pm .06 \mu \mathrm{m})$. Thus the morphologic change was specifically related to active MPO exposure. The degree of elongation produced by the MPO system was not as dramatic as can be observed with PBP3-selective antibiotics, but MPO-mediated damage to other PBPs and to microbial metabolism at other sites (4) may have limited further growth and elongation of the organisms. $P$. aeruginosa PBPs are thought to have similar functions to their correspondingly numbered counterparts in $E$. coli. $P$. aeruginosa showed no change in length after MPO exposure (baseline $=2.03 \pm .04 \mu \mathrm{m}$, change at $30 \mathrm{~min}=0.01 \pm .04 \mu \mathrm{m}$ ), consistent with the lack of significant early PBP3 inactivation in $P$. aeruginosa.

\section{Discussion}

The neutrophil-derived MPO system has antimicrobial effects against a broad range of microorganisms (1). The precise nature of the lesions leading to bacterial death have been difficult to define. Here, we have demonstrated that the MPO system inhibits the penicillin-binding activity of multiple bacterial PBPs. The loss of penicillin binding very likely reflects enzymatic inactivation of the PBPs. In rare instances, however, using specially selected mutants, enzymatic activity and penicillin binding can be dissociated (23). MPO-mediated PBP inacti- vation does not occur with a control MPO system, lacking chloride, in which $\mathrm{H}_{2} \mathrm{O}_{2}$ and MPO are present, but no killing takes place. Nor is the effect simply a nonspecific manifestation of cell death, since bactericidal systems containing gentamicin or xanthine oxidase/acetaldehyde are equally ineffective in inactivating PBPs. Thus, PBP inactivation is related to exposure to a bactericidally active MPO system.

Relationships between inactivation of PBPs and loss of viability may be complex $(5,23)$. In $E$. coli, where it has been best studied, each high molecular weight PBP: 1, 2, and 3, has been considered essential to survival under usual growth conditions, while PBPs 4,5 , and 6 have not. Inactivation of PBP 1 or 2 by antibiotics usually produces cell lysis (5) while PBP3 inactivation may result in loss of viability independent of cytolysis (24). MPO-mediated killing of $E$. coli correlated best with loss of PBP3 activity, although inactivation of no single PBP could account fully for microbicidal activity. An MPO-mediated distortion of the overall pattern of PBP synthetic and remodeling functions, rather than inhibition of a single PBP, may be responsible for cell death. Indeed, synergistic antibiotic-induced microbicidal effects involving inhibition of multiple PBPs have been described previously (23). Analagous synergistic events are likely to play a role in MPO-mediated antimicrobial activity.

E. coli morphology is affected by the MPO system. An increase in $E$. coli length is seen with progressive exposure to 
MPO. Once again, this process occurs solely in the presence of an active MPO system, since neither the control MPO system nor microbicidal systems containing gentamicin or xanthine oxidase/acetaldehyde have significant effects on cell length. This progressive lengthening of $E$. coli is consistent with the preferential inhibition of PBP3 induced by MPO, since the latter should result in a diminution in the synthesis of cross walls while cylindrical wall synthesis continues.

The MPO system inactivates PBPs in a variety of bacteria, including Gram-negatives ( $E$. coli and $P$. aeruginosa) and a Gram-positive (S. aureus). However, the pattern of PBP inactivation differs amongst bacterial species. While PBP3 is inactivated most rapidly in $E$. coli, $\mathrm{PBP} 3$ in $P$. aeruginosa is more resistant to MPO-derived oxidants, and PBPs $1 \mathrm{a}, 1 \mathrm{~b}, 4$, and 5 of $P$. aeruginos $a$ are inactivated more rapidly than their counterparts in $E$. coli. Since correspondingly numbered PBPs in $E$. coli and $P$. aeruginosa are thought to have similar functions (25), the reason for this discrepancy in the pattern of MPO-mediated PBP inactivation is unclear. Different locations of critical, sensitive residues in the two organisms, with resulting differences in accessibility to MPO-derived oxidants, could explain this disparity.

$P$. aeruginosa PBPs $1 \mathrm{a}$ and $\mathrm{lb}$ are thought to be critical for bacterial survival, and their inhibition by MPO-derived oxidants would be expected to lead to cell death, consistent with the good correlation seen between loss of PBP $1 \mathrm{a}$ and $1 \mathrm{~b}$ activity and viability. Studies of $S$. aureus have suggested that PBP2 is the primary transpeptidase, PBP3 is involved in septation, and PBPs 1 and 4 are nonessential (26). Again, MPO-mediated inhibition of a critical PBP, in this case PBP2, would be expected to lead to cell death, and is consistent with the good correlation between loss of PBP2 activity and killing.

In summary, the penicillin binding capability of essential $E$. coli, $P$. aeruginosa, and $S$. aureus PBPs is lost in the presence of MPO-derived oxidants at rates approximating loss of microbial viability. MPO-derived oxidants presumably attack multiple bacterial targets simultaneously and the resultant oxidation events probably act in concert to effect loss of viability. The overall rapidity of PBP inactivation, the independent evidence from antibiotic studies demonstrating the lethality of PBP inactivation, and the suggestive morphologic changes in $E$. coli induced by MPO-derived oxidants all argue that PBP inactivation is a major mechanism of MPO-mediated microbicidal action. The extent to which PBP-inactivation is a feature of microbicidal activity mediated by intact neutrophils remains to be determined. However, preliminary studies have established that PBP activity of membranes from $E$. coli phagocytosed by human PMNs declines in parallel with microbial viability (unpublished observation). PBPs' vulnerability to inactivation appears to have been exploited by antimicrobial systems as diverse as mold-associated $\beta$-lactam antibiotics and mammalian phagocyte-associated MPO.

\section{Acknowledgments}

We thank Paul Mendelman and Donald Chaffin for assistance with penicillin-binding fluorographic methods and helpful discussions, Bryce Michel for technical assistance, and Marsha Faamuli for assistance in preparation of the manuscript.

This work was supported by grant AI 25606 from the National Institute of Allergy and Infectious Diseases.

\section{References}

1. Klebanoff, S. J., and R. A. Clark. 1978. The Neutrophil: Function and Clinical Disorders. North-Holland Publishing Co., Amsterdam.

2. Harrison, J. E., and J. Schultz. 1976. Studies on the chlorinating activity of myeloperoxidase. J. Biol. Chem. 251:1371-1374.

3. Thomas, E. L. 1979. Myeloperoxidase, hydrogen peroxide, chloride antimicrobial system: nitrogen-chlorine derivatives of bacterial components in bactericidal action against Escherichia coli. Infect. Immun. 23:522-531.

4. Hurst, J. K., and W. C. Barrette, Jr. 1989. Leukocytic oxygen activation and microbicidal oxidative toxins. CRC Crit. Rev. Biochem. Mol. Biol. 24:271328.

5. Tomasz, A. 1986. Penicillin-binding proteins and the antibacterial effectiveness of $\beta$-lactam antibiotics. Rev. Infect. Dis. 8:S260-S278.

6. Frère, J. M., and B. Joris. 1985. Penicillin-sensitive enzymes in peptidoglycan biosynthesis. CRC Crit. Rev. Microbiol. 11:299-396.

7. Spratt, B. G. 1983. Penicillin-binding proteins and the future of $\beta$-lactam antibiotics. J. Gen. Microbiol. 129:1247-1260.

8. Jabes, D., S. Nachman, and A. Tomasz. 1989. Penicillin-binding protein families: evidence for the clonal nature of penicillin resistance in clinical isolates of pneumococci. J. Infect. Dis. 159:16-25.

9. Brown, D. F. J., and P. E. Reynolds. 1980 . Intrinsic resistance to $\beta$-lactam antibiotics in Staphylococcus aureus. FEBS (Fed. Eur. Biochem. Soc.) Lett. 122:275-279.

10. Mendelman, P., D. O. Chaffin, T. L. Stull, C. E. Rubens, K. D. Mack, and A. L. Smith. 1984. Characterization of non- $\beta$-lactamase-mediated ampicillin resistance in Haemophilus influenzae. Antimicrob. Agents Chemother. 26:235-244.

11. Williamson, R., C. L. Bouguenec, L. Gutmann, and T. Horaud. 1985. One or two low affinity penicillin-binding proteins may be responsible for the range of susceptibility of Enterococcus faecium to benzylpenicillin. J. Gen. Microbiol. 131:1933-1940.

12. Dougherty, T. J., A. E. Koller, and A. Tomasz. 1980. Penicillin-binding proteins of penicillin-susceptible and intrinsically resistant Neisseria gonorrhoeae. Antimicrob. Agents Chemother. 18:730-737.

13. Godfrey, A. J., L. E. Bryan, and H. R. Rabin. 1981. $\beta$-lactam-resistant Pseudomonas aeruginosa with modified penicillin-binding proteins emenging during cystic fibrosis treatment. Antimicrob. Agents Chemother. 19:705-711.

14. Rakita, R. M., B. R. Michel, and H. Rosen. 1990. Differential inactivation of Escherichia coli membrane dehydrogenases by a myeloperoxidase-mediated antimicrobial system. Biochemistry. 29:1075-1080.

15. Klebanoff, S. J., A. M. Waltersdorph, and H. Rosen. 1984. Antimicrobial activity of myeloperoxidase. Methods Enzymol. 105:399-403.

16. Rosen, H., and S. J. Klebanoff. 1981. Role of iron and ethylenediaminetetraacetic acid in the bactericidal activity of a superoxide anion-generating system Arch. Biochem. Biophys. 208:512-519.

17. Hinson, D. L., and R. J. Webber. 1988. Miniaturization of the BCA protein assay. Biotechniques. 6:14-16.

18. Laemmli, U. K. 1970 . Cleavage of structural proteins during the assembly of the head of bacteriophage T4. Nature (Lond.). 227:680-685.

19. Lleo, M. M., P. Canepari, and G. Satta. 1990. Bacterial cell shape regulation: testing of additional predictions unique to the two-competing-sites mode for peptidoglycan assembly and isolation of conditional rod-shaped mutants from wild-type cocci. J. Bacteriol. 172:3758-3771.

20. Spratt, B. G. 1975. Distinct penicillin binding proteins involved in the division, elongation, and shape of Esherichia coli K-12. Proc. Natl. Acad. Sci. USA. 72:2999-3003.

21. Cooper, S. 1989. The constrained loop: an explanation of the overshoot in cell length during a shift-up of Escherichia coli. J. Bacteriol. 171:5239-5243.

22. Imlay, J. A., and S. Linn. 1987. Mutagenesis and stress responses induced in Escherichia coli by hydrogen peroxide. J. Bacteriol. 169:2967-2976.

23. Spratt, B. G., and K. D. Cromie. 1988. Penicillin-binding proteins of gram-negative bacteria. Rev. Infect. Dis. 10:699-711.

24. Curtis, N. A. C., R. L. Eisenstadt, K. A. Turner, and A. J. White. 1985. Inhibition of penicillin-binding protein 3 of Escherichia coli K-12. Effects upon growth, viability, and outer membrane function. J. Antimicrob. Chemother. 16:287-296.

25. Noguchi, H., M. Matsuhashi, and S. Mitsuhashi. 1979. Comparative studies of penicillin-binding proteins in Pseudomonas aeruginosa and Escherichia coli. Eur. J. Biochem. 100:41-49.

26. Georgopapadakou, N. H., B. A. Dix, and Y. R. Mauriz. 1986. Possible physiological functions of penicillin-binding proteins in Staphylococcus aureus. Antimicrob. Agents Chemother. 29:333-336.

27. Rosen, H., R. M. Rakita, A. M. Waltersdorph, and S. J. Klebanoff. 1987. Myeloperoxidase-mediated damage to the succinate oxidase system of Escherichia coli: evidence for selective inactivation of the dehydrogenase component. J. Biol. Chem. 262:15004-15010.

28. Spratt, B. G. 1977. Properties of the penicillin-binding proteins of Escherichia coli K-12. Eur. J. Biochem. 72:341-352. 